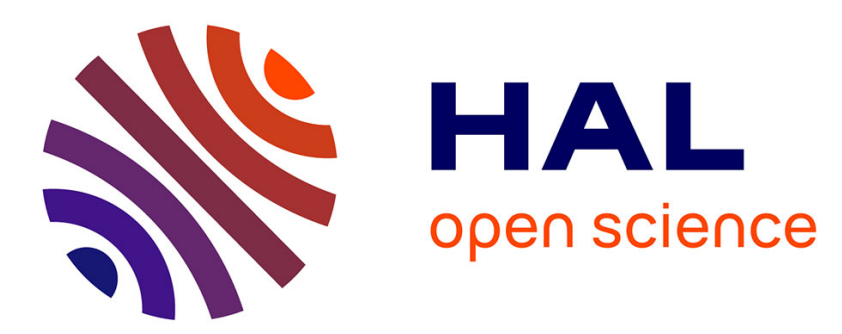

\title{
Characterization of oxyde films and conversion layers on aluminium alloys
}

J. de Laet, G. Goeminne, H. Terryn, J. Vereecken

\section{To cite this version:}

J. de Laet, G. Goeminne, H. Terryn, J. Vereecken. Characterization of oxyde films and conversion layers on aluminium alloys. Journal de Physique IV Proceedings, 1993, 03 (C7), pp.C7-981-C7-985. 10.1051/jp4:19937151 . jpa-00251774

\section{HAL Id: jpa-00251774 https://hal.science/jpa-00251774}

Submitted on 1 Jan 1993

HAL is a multi-disciplinary open access archive for the deposit and dissemination of scientific research documents, whether they are published or not. The documents may come from teaching and research institutions in France or abroad, or from public or private research centers.
L'archive ouverte pluridisciplinaire HAL, est destinée au dépôt et à la diffusion de documents scientifiques de niveau recherche, publiés ou non, émanant des établissements d'enseignement et de recherche français ou étrangers, des laboratoires publics ou privés. 


\title{
Characterization of oxyde films and conversion layers on aluminium alloys
}

\author{
J. DE LAET, G. GOEMINNE, H. TERRYN and J. VEREECKEN
}

Vrije Universiteit Brussel, Dept. Metallurgy, Electrochemistry and Materials Science, Pleinlaan 2, 1050 Brussels, Belgium

\begin{abstract}
Corrosion resistance and specific functional properties (dielectrical and decorative properties, adhesion, wear resistance) of aluminium alloys can be improved by surface treatments as electrochemical or chemical conversion reaction.

The purpose of this study is to discuss the applicability of spectroscopic ellipsometry (SE) and electrochemical impedance spectrometry (EIS) for the characterization of the obtained conversion surface layers.

It can be concluded that SE yields an accurate characterization for the thickness and the interfacial properties of both the barrier an porous oxide layer. The EIS allows to measure and to determine the sealing grade of the porous layer. These two complementary techniques can be used to investigate the growth mechanism of phosphate chromate conversion layers.
\end{abstract}

\section{INTRODUCTION}

Corrosion resistance and specific functional properties (dielectric and decorative properties, adhesion, wear resistance) of aluminium alloys can be improved by several surface treatments.

Each of these treatments : roughening, anodizing, sealing, conversion reactions induces chemical and morphological changes at the surface which are strongly correlated with the surfaces properties. To deal with this kind of investigations a number of analytical techniques have been used successfully during the last years [1,2]. Yet some methods are destructive, can not be used in situ and require a long and delicate specimen preparation. The purpose of this study is to discuss the applicability of spectroscopic ellipsometry (SE) and electrochemical impedance spectroscopy (EIS) for the characterization of oxide and conversion layers on aluminium alloys. 


\section{EXPERIMENTAL}

The principles of SE [3] and EIS [4] were already extensively explained. Smooth, clean and highly reflecting aluminium substrates suited for ellipsometry were prepared by vapor deposition of $2-3 \mu \mathrm{m}$ thick aluminium films on silicon wafers.

Barrier oxide layer were formed in a $3 \%$ ammoniumtartrate solution of $\mathrm{pH} 5.5$ at $22^{\circ} \mathrm{C}$. The porous oxide films were grown in a $20 \%$ sulphuric acid solution at $25^{\circ} \mathrm{C}$. Sealing of this porous layer occurred in water at $95^{\circ} \mathrm{C}$.

Aluminium surface was chemically converted in a $16 \mathrm{~g} / \mathrm{l}$ chromic acid / phosphoric acid mixture containing $0.25 \mathrm{~g} / \mathrm{HF}$ at $60^{\circ} \mathrm{C}$.

\section{RESULTS}

In order to show the complementary of the techniques to investigate in situ surface treatments of aluminium alloys SE and EIS (Bode diagrams) spectra of chemical conversion reaction are presented in figures 1 and 2 with as parameters the immersion time.

These results of SE can be interpreted with the SELLMEIER relation [5] (figure 3) and those of EIS with an equivalent network [6] (figure 4). Other results concerning these surface treatments of aluminium alloys can be found in several publications $[7,8]$.

\section{CONCLUSIONS}

It can be concluded that SE yields an accurate characterization for the thickness and the interfacial properties of both the barrier and porous oxide layer. The EIS allows to measure the barrier layer thickness and to determine the sealing grade of the porous layer.

These two complementary techniques can be used to investigate the growth mechanism of phosphate chromate conversion layer.

\section{REFERENCES}

[1] THOMPSON G.E. and WOOD G.C., Treatise on Materials Science and Technology, 23, Academic Press, London, England (1983) Chapter 5

[2] TERRYN H., VEREECKEN J. and VAN LANDUYT J., Journal of the Insitute of Metal Finishing, 68, part 1 (1990) 33.

[3] DE LAET J., VANHELlEMONT J., TERRYN H. and VEREECKEN J., Appl. Phys. A, 54 (1991) 72 .

[4] VAN DER LINDEN B., TERRYN H. and VEREECKEN J., Journal Applied Electrochemistry 20 (1990) 798.

[5] DOBROWOLSKI J.A., HO F.C. and WALDORF A., Applied Optics, 22 (1983) 3191.

[6] GOEMINNE G., TERRYN H. and VEREECKEN J., Proc. EAST Meeting on Surface Treatments of Aluminium, Swabisch-Gmund, Germany, 12-13 November, 1992, to be published.

[7] DE LAET J., VANHELLEMONT J., TERRYN H. and VEREECKEN J., Surfance and Interface Analysis, 19 (1992) 445.

[8] DE LAET J., SCHEERS J., TERRYN H. and VEREECKEN J, to be published in Electrocemica Acta, 38. 
a

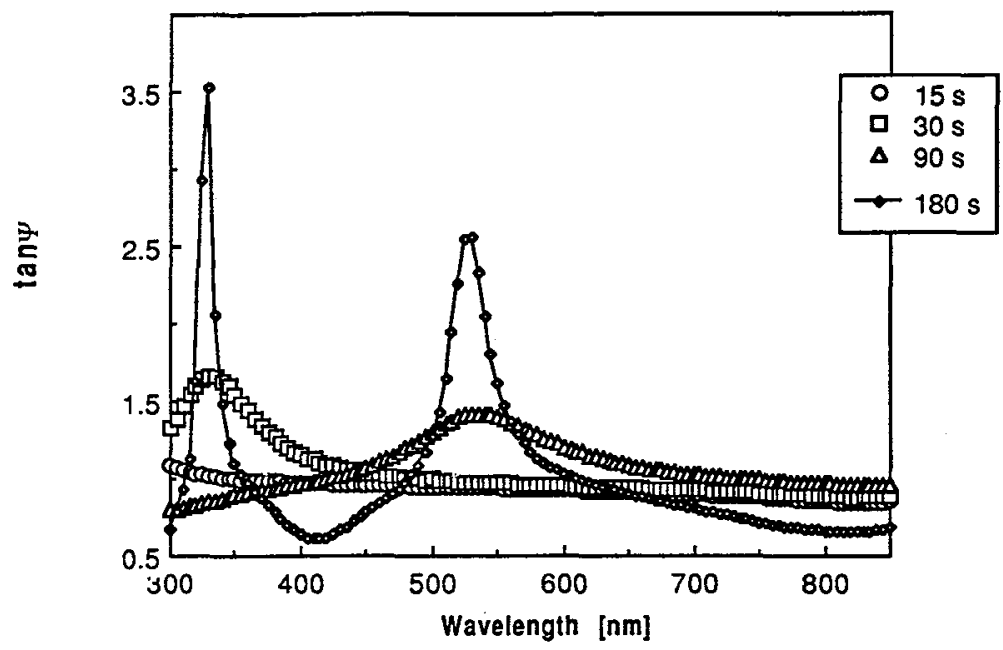

b

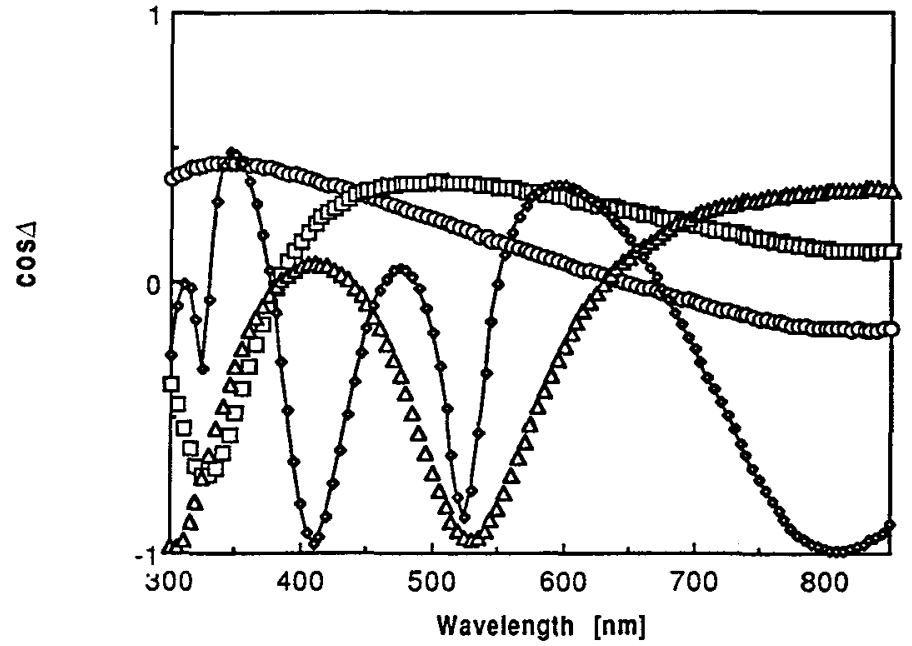

Figure 1 : Ellipsometric spectra for a conversion in a $0.34 \mathrm{ml} \mathrm{HF} /$ bath solution at $50^{\circ} \mathrm{C}$ for different immersion times.
a. $\tan \Psi$
b. $\cos \Delta$ 
a

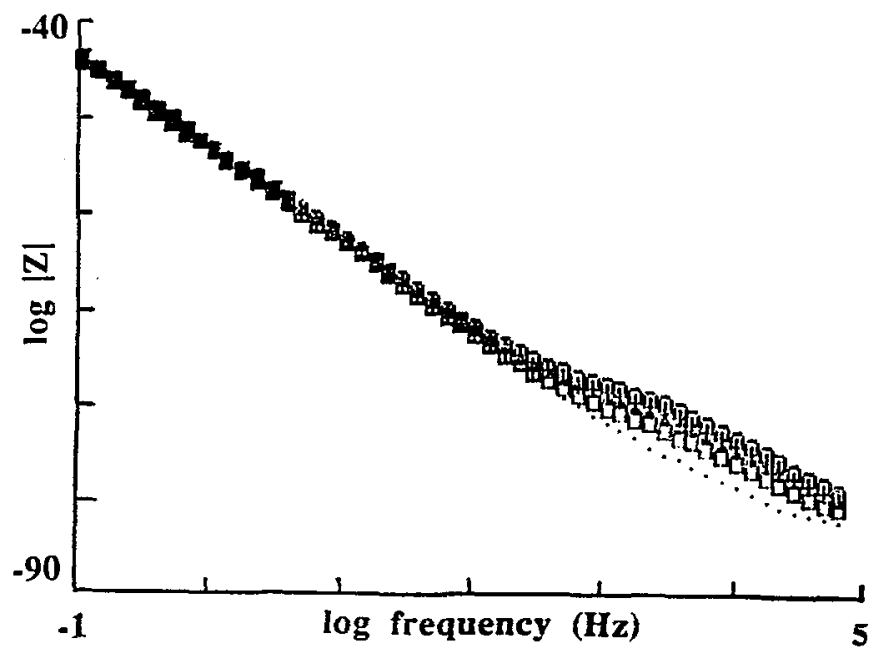

b

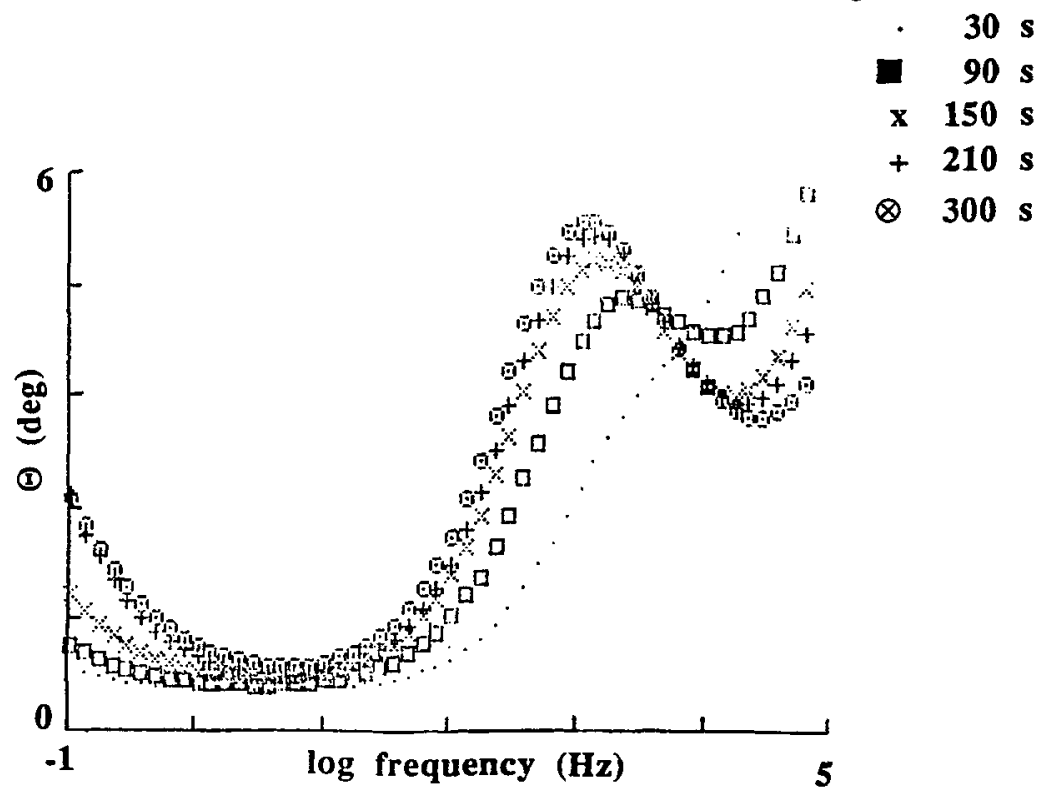

Figure 2 : Impedance for a conversion in a $0.34 \mathrm{mi}$ HF $/$ bath solution at $50^{\circ} \mathrm{C}$ for different immersion times.

a. Bode-amplinude diagram

b. Bode-phase diagram 


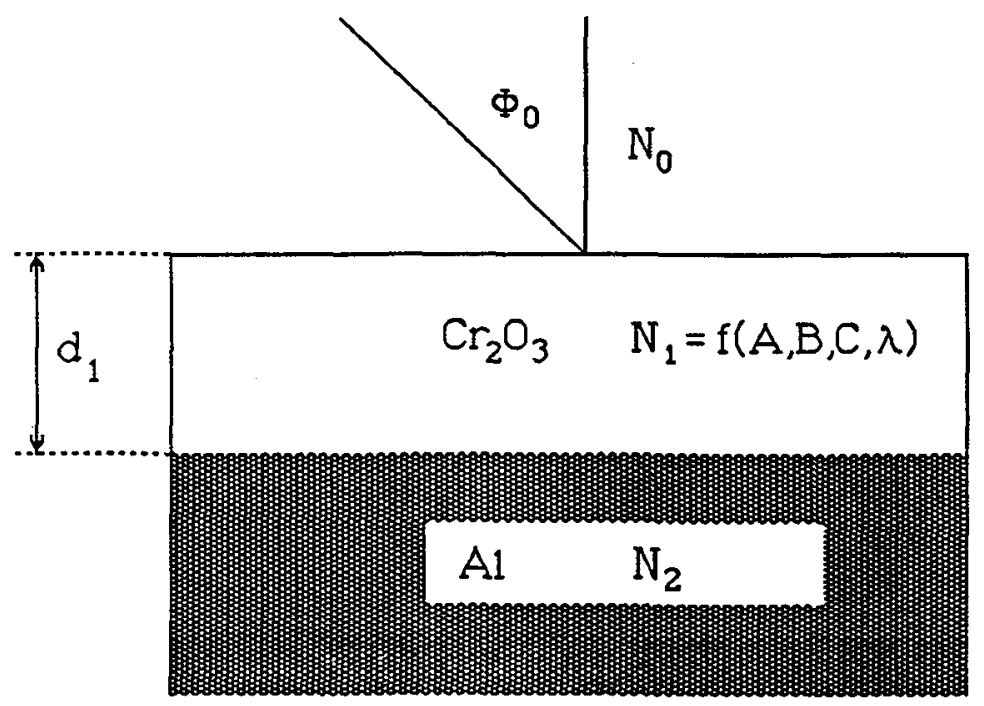

Figure 3 : Ellipsometric model for converteci aluminium.

$\Phi_{0}:$ angle of incidence

$\mathrm{N}_{0}$ : refractive index of ambient medium

$N_{1}$ : refractive index of conversion layer, modelled by the Sellmeier dispersion relation $\mathrm{N}_{2}$ : complex refractive index of the substrate

$d_{1}:$ thickness of the conversion film

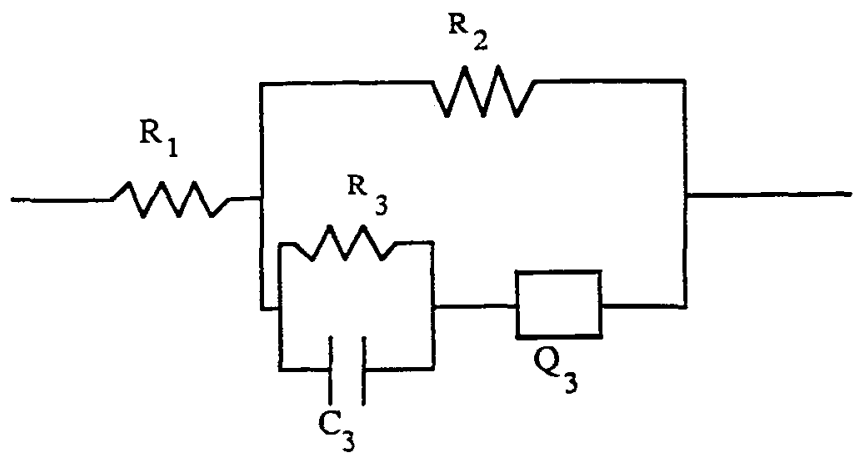

Figure 4: Impedance model for converted aluminium immersed in an electrolyte.

$R_{1}$ : resistance of the electrolyte

$\mathbf{R}_{2}$ : resistance of imperfections in the layer

$\mathbf{R}_{3}, \mathbf{C}_{3}$ : resistance and capacity of the conversion layer

$Q_{3}$ : impedance in the pores of the conversion layer 